\title{
Development of Ultra-Thin Glass-Coated Amorphous Microwires for High Frequency Magnetic Sensors Applications
}

\author{
V. Zhukova*, ${ }^{* 1}$ M. Ipatov ${ }^{2}$, C. García ${ }^{2}$ J. Gonzalez ${ }^{2}$, J. M. Blanco ${ }^{1}$ and A. Zhukov ${ }^{2,3}$ \\ ${ }^{1}$ Dpto. de Física Aplicada, EUPDS, Universidad del País Vasco, 20009 San Sebastián, Spain \\ ${ }^{2}$ Dpto. de Física de Materiales, Fac. Químicas, Universidad del País Vasco, 20009 San Sebastián, Spain \\ ${ }^{3}$ TAMAG Ibérica S.L., Parque Tecnológico de Miramón, Paseo Mikeletegi 56, $1^{a}$ Planta, 20009 San Sebastián, Spain
}

\begin{abstract}
The giant magneto-impedance (GMI) effect has been studied in 3 different families of amorphous wires: conventional amorphous wires $(125 \mu \mathrm{m}$ in diameter), cold drawn wires (50 and $20 \mu \mathrm{m}$ in diameter) and thin glass coated amorphous microwires (with metallic nucleus diameter of about $15 \mu \mathrm{m}$ ). These wires have been investigated in the frequency range $1-500 \mathrm{MHz}$. A remarkable difference in the magnetic field dependence of the GMI effect can be attributed to the different magnetoelastic anisotropy of these three families of the wires.
\end{abstract}

Keywords: Amorphous wires and microwires, giant magneto-impedance, skin effect.

\section{INTRODUCTION}

The study of giant magneto-impedance effect (GMI) has become a topic of intensive research in the field of applied magnetism over the past years [1,2]. This GMI effect consists of a large change in the electric impedance of a magnetic conductor when the material is subjected to an axial $d c$ magnetic field. It has been recognized that the large sensitivity of the total impedance of a soft magnetic conductor at low magnetic fields and high frequencies of the driving $a c$ current originates from the dependence of the transverse magnetic permeability upon the $d c$ magnetic field and skin effect. The main interest of the GMI effect is related to the high sensitivity of the impedance to an applied magnetic field, easily achieving up to $300 \%$ relative change of impedance in amorphous wires with vanishing magnetostriction, which is common in the $\left(\mathrm{Co}_{0.94} \mathrm{Fe}_{0.06}\right)_{72.5} \mathrm{~B}_{15} \mathrm{Si}_{12.5}$ conventional amorphous wire.

Since the re-discovery of the magneto-impedance effect in 1994, a number of investigations and developments in this direction have been widely performed by different groups. Thus, a CMOC IC (Complimentary Metal Oxide Silicon Integtrated ciruits) with pulsed current operation was established for the MI sensors [3]. The stress-impedance (SI) and torsion impedance (TI) effects, showing a high sensitivity of the impedance to the applied stress with a strange gauge factor of 2000-4000, have been found in amorphous wires [4].

As a result, the GMI and SI sensors in the CMOC IC circuitry with advantageous features comparing to conventional magnetic sensors have been developed by different companies [4]. Main applications are related to the detection of the magnetic fields, small weights and vibrations, and many branches of the industry. e.g., car industry and medicine are main consumers of these sensors. Among the almost 100 applications, the following sensors are currently in progress: portable digital display of the terrestrial magnetic

*Address correspondence to this author at the Dpto. de Física Aplicada, EUPDS, Universidad del País Vasco, 20009 San Sebastián, Spain; E-mail: arkadi.joukov@ehu.es field, brain tumor sensor, secondary current sensor for the induction motor control, car passing measurement and recording disk, finger-tip blood vessel pulsation, mechanoencephalogram sensor, etc.

Main applications were developed for the amorphous wires, where the highest GMI effect was generally observed. In the meantime, generally an inferior GMI effect has been observed for other amorphous magnetic materials without special treatment, such as amorphous ribbons and microwires, where GMI ratio is generally less than 60\% [4]. The significant GMI ratio should be attributed to the enhanced circular magnetic permeability observed in amorphous wires. In fact, most experimental and theoretical results [5] have pointed out that the good magnetic softness is directly related to the GMI effect. For instance, it was theoretically shown in [5] that the axial dependence of the GMI spectra is mainly determined by the type of magnetic anisotropy. It was shown particularly, that the circumferential anisotropy leads to the observation of the maximum of the real component of wire impedance (and consequently of the GMI ratio) as a function of the external magnetic field. In contrast, in the case of axial magnetic anisotropy the maximum value of the GMI ratio corresponds to zero magnetic fields [5], i.e. results in a monotonic decay of the GMI ratio with the axial magnetic field. Consequently, non-diagonal components of the magnetic permeability tensor and impedance tensor were introduced in $[6,7]$ in order to describe such circumferential anisotropy. Therefore, for the samples with a well-defined maximum on the axial field dependence of GMI ratio, the importance of the non-diagonal components of the permeability tensor should be noted. Besides in order to achieve high GMI effect, the magnetic anisotropy should be as small as possible.

Circular domain structure with high circumferential permeability proved to be very favorable for the highest GMI effect [1-2]. Such domain configuration is typical for the nearly-zero magnetostrictive amorphous wires mainly produced by Japanise company Unitika LTD [1-3]. On the other hand, these amorphous wires with vanishing magnetostriction constant present best magnetic softness [4]. It has been 
clearly demonstrated by T. Yoshinaga et al. [8] by chemical etching of $30 \mu \mathrm{m}\left(\mathrm{Co}_{0.94} \mathrm{Fe}_{0.06}\right)_{72.5} \mathrm{Si}_{12.5} \mathrm{~B}_{15}$ wire in $10 \%$ $\mathrm{HNO}_{3}$, that the removing of the external layer with high transverse permeability results in simultaneous degradation of its magnetic softness, decrease of MI effect $(\Delta Z / Z)$ and increase of the squareness ratio and coercivity. Besides, it was recently demonstrated that the applied stresses can significantly affect the GMI effect of conventional amorphous wires and glass coated microwires $[9,10]$.

As has been mentioned, initially the GMI effect was interpreted in terms of the classical skin effect in a magnetic conductor assuming scalar character for the magnetic permeability, as a consequence of the change in the penetration depth of the $a c$ current caused by the $d c$ applied magnetic field. The electrical impedance, Z, of a magnetic conductor in this case is given by $[1,2]$ :

$\mathrm{Z}=\mathrm{R}_{\mathrm{dc}} \mathrm{kr} \mathrm{J}(\mathrm{kr}) / 2 \mathrm{~J}_{1}(\mathrm{kr})$

with $\mathrm{k}=(1+\mathrm{j}) / \delta$, where $\mathrm{J}_{\mathrm{O}}$ and $\mathrm{J}_{1}$ are the Bessel functions, $\mathrm{r}$ -wire's radius and $\delta$ the penetration depth given by:

$\delta=\left(\pi \sigma \mu_{\phi} \mathrm{f}\right)^{-1 / 2}$

where $\sigma$ is the electrical conductivity, $f$ the frequency of the current along the sample, and $\mu_{\phi}$ the circular magnetic permeability assumed to be scalar. The $d c$ applied magnetic field introduces significant changes in the circular permeability, $\mu_{\phi}$. Therefore, the penetration depth also changes through and finally results in a change of $Z$ [1,2]. Recently this "scalar" model was significantly modified by taking into account the tensor origin of the magnetic permeability and magneto impedance $[6,7]$.

It is worth mentioning that the shape of the magnetic field dependence of the GMI ratio, $\Delta Z / Z$, at least for the small negative magnetostriction constant has a nonmonotonic shape with the maximum at the field corresponding to the circular magnetic anisotropy field. Therefore we assume that the shape of the magnetic field dependence of $\Delta Z / Z$ should be sensitive to the magnetic anisotropy especially in the surface layer of the sample [1].

The presently strong trend to miniaturization of magnetic elements has resulted in the development of the TaylorUlitovsky method allowing to produce tiny ferromagnetic metallic wires $(1 \div 30 \mu \mathrm{m}$ in diameter) covered by an insulating glass coating presenting GMI effect $[4,11,12]$. Recent significant progress in tailoring of magnetically soft glass coated microwires fabricated by this method enabled to significantly enhance the GMI ratio (up to about $600 \%$ ) [4,11]. Such a high GMI effect is generally observed in Co-rich metallic nucleus compositions with vanishing magnetostriction constant, while Fe-rich amorphous microwires with rectangular hysteresis loop exhibit rather poor initial magnetic permeability and do not show GMI effect due to the strong longitudinal magnetic anisotropy [4].

In this paper we review and analyze the results on GMI effect in different families of thin wires by paying special attention to tailoring the GMI ratio of thin glass-coated amorphous microwires (with the metallic nucleus diameter about $5-25 \mu \mathrm{m}$ ) by choosing the sample geometry (thickness of glass coating) and conditions of heat treatment by the Joule heating.

\section{GMI EFFECT IN DIFFERENT FAMILIES OF WIRES}

The GMI effect is related intrinsically to the hysteresis loops of the samples. Typical hysteresis loops of 3 families of studied wires are presented in Fig. (1).
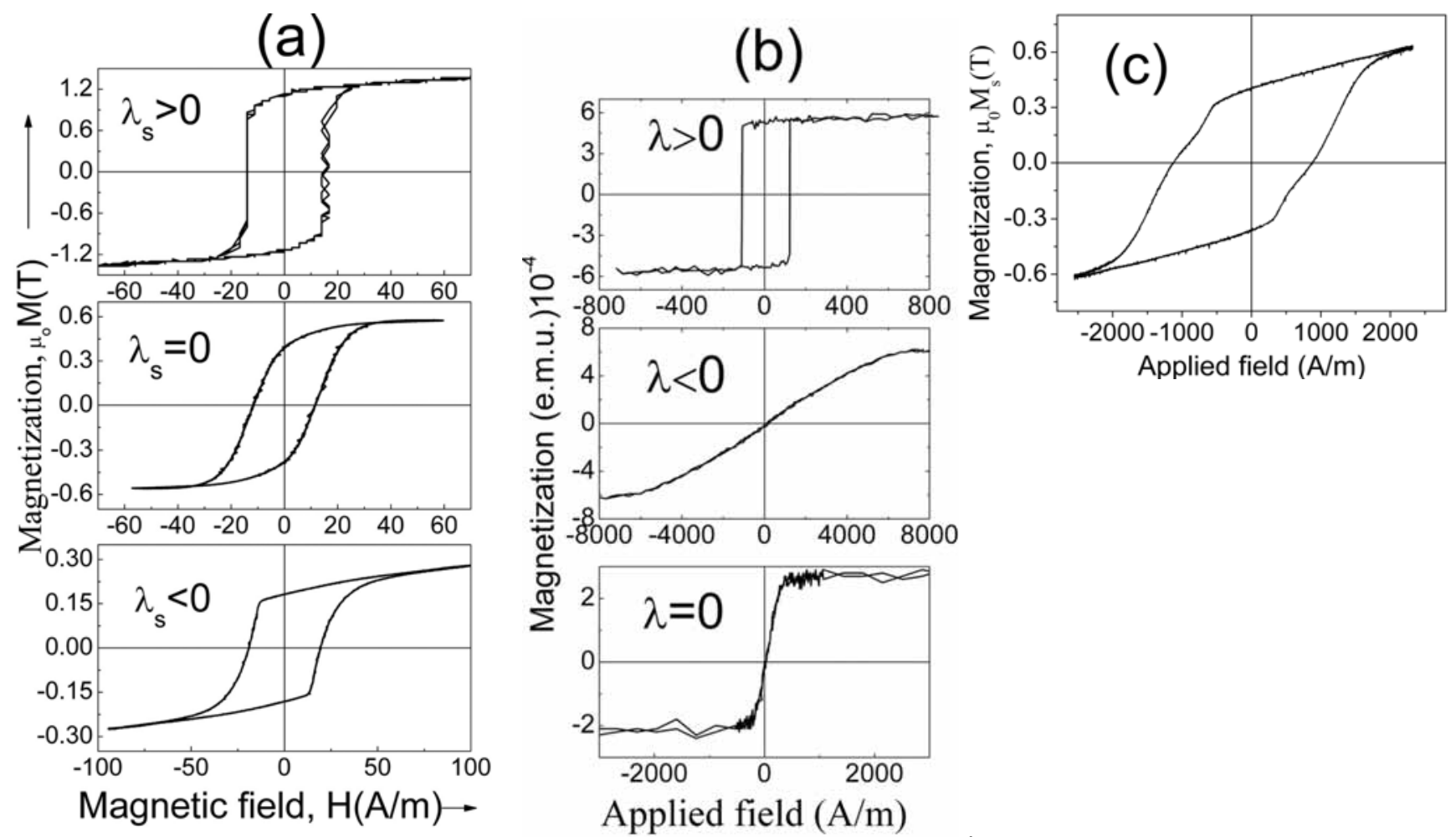

Fig. (1). Hysteresis loops of (a) conventional Fe-rich $\left(\lambda_{\mathrm{s}}>0\right)$, Fe-Co-rich $\left(\lambda_{\mathrm{s}} \approx 0\right)$ and Co-rich $\left(\lambda_{\mathrm{s}}<0\right)$ amorphous wires, (b) thin glass coated Fe-rich $\left(\lambda_{\mathrm{s}}>0\right)$, Fe-Co-rich $\left(\lambda_{\mathrm{s}} \approx 0\right)$ and Co-rich $\left(\lambda_{\mathrm{s}}<0\right)$ microwires and $(\mathbf{c})$ Fe-rich cold drawn wires. 
(a)

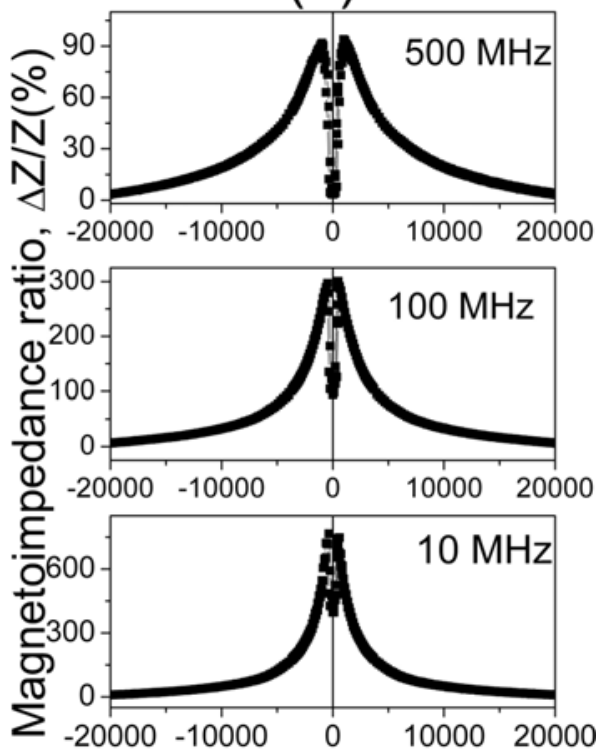

Magnetic field $(\mathrm{A} / \mathrm{m})$ (b)
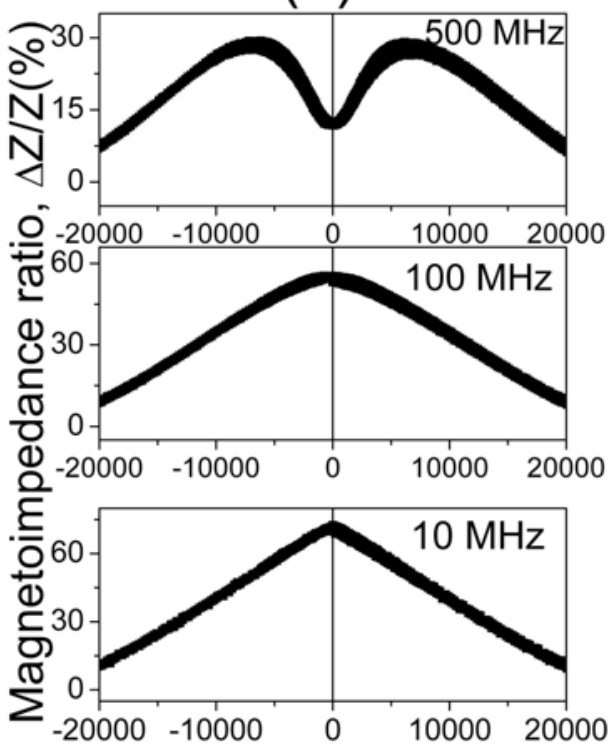

Magnetic field $(\mathrm{A} / \mathrm{m})$

Fig. (2). $D C$ magnetic tield dependence of the impedance of the conventional $\left(\mathrm{Co}_{0.94} \mathrm{Fe}_{0.06}\right)_{72.5} \mathrm{Si}_{12.5} \mathrm{~B}_{15}(\mathbf{a})$ and $\mathrm{Fe}_{77.5} \mathrm{~B}_{15} \mathrm{Si}_{7.5}(\mathbf{b})$ amorphous wires with diameter of $125 \mu \mathrm{m}$.

As can be observed, Fe- and Co-rich wires have rectangular hysteresis loops, Co-Fe-rich wires exhibit enhanced magnetic softness (Fig. 1a), and cold-drawn wires exhibit enhanced coercivity (Fig. 1c). The chemical composition of glass-coated microwires drastically affects their magnetization curves: the hysteresis loop changes from rectangular for Fe-rich compositions to almost unhysteretic in Co-rich compositions (Fig. 1b).

The magneto impedance ratio, $\Delta Z / Z$, has been defined as:

$\Delta \mathrm{Z} / \mathrm{Z}=\left[\mathrm{Z}(\mathrm{H})-\mathrm{Z}\left(\mathrm{H}_{\max }\right)\right] / \mathrm{Z}\left(\mathrm{H}_{\max }\right)$.

The dependence of the magneto-impedance ratio, $\Delta Z / Z$, measured at different frequencies, $f$, for as-cast $\mathrm{Fe}_{77.5} \mathrm{~B}_{15} \mathrm{Si}_{7.5}$

(a)

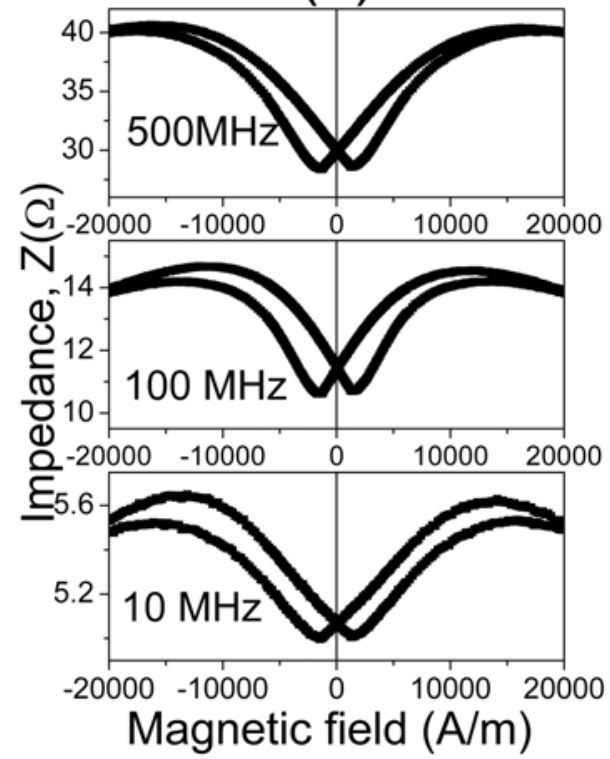

and $\left(\mathrm{Co}_{0.94} \mathrm{Fe}_{0.06}\right)_{72.5} \mathrm{Si}_{12.5} \mathrm{~B}_{15}$ amorphous conventional wires are presented in the Fig. (2) as a function of magnetic field, $H$. In $\mathrm{Fe}_{77.5} \mathrm{~B}_{15} \mathrm{Si}_{7.5}$ amorphous wires between $10 \mathrm{MHz}$ and $100 \mathrm{MHz}$ the GMI effect presents monotonic decay of the impedance with magnetic field, while at frequencies above $100 \mathrm{MHz}$ such dependence changes the character, showing a maximum at certain $d c$ axial magnetic field, which depends on the frequency (see Fig. 2).

On the other hand, Fe-rich cold drawn wires show a maximum on the field dependence of the impedance, $\mathrm{Z}$, even at $10 \mathrm{MHz}$ with considerable hysteresis (see Fig. 3).

(b)

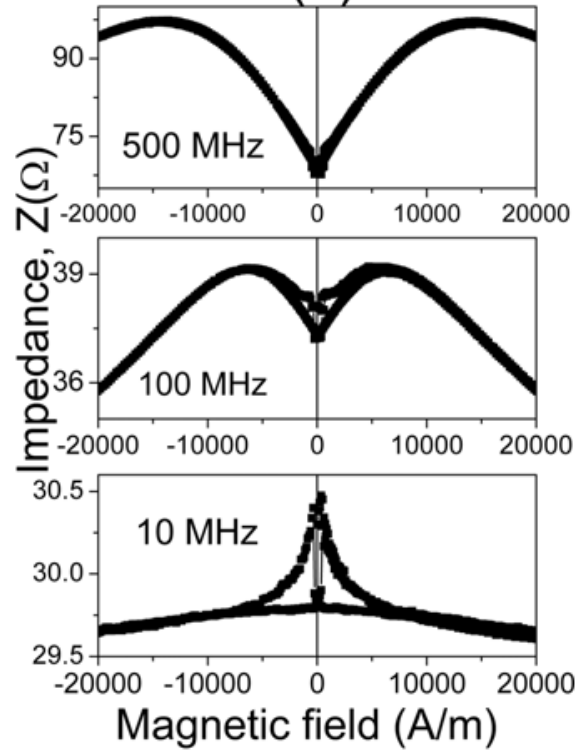

Fig. (3). $D C$ magnetic field dependence of the impedance of the cold-drawn amorphous wire $\mathrm{Fe}_{77.5} \mathrm{~B}_{15} \mathrm{Si}_{7.5}$ with diameter of $50 \mu \mathrm{m}(\mathbf{a})$ and 30 $\mu \mathrm{m}(\mathbf{b})$. 
(a)
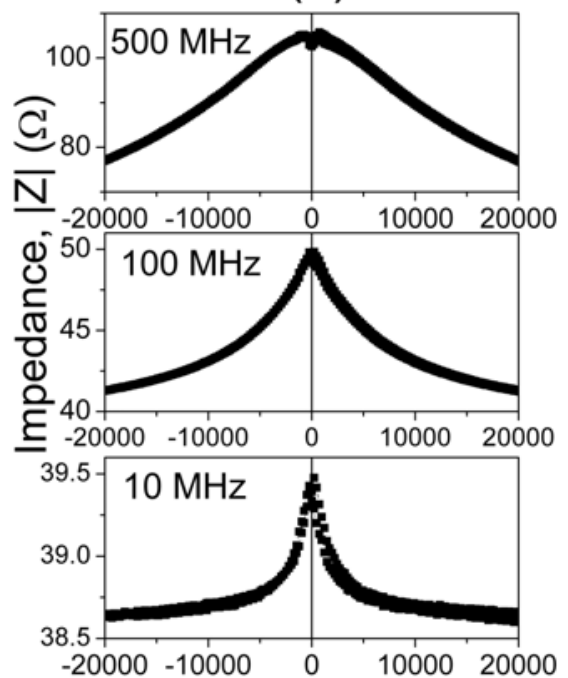

Axial magnetic field $(\mathrm{A} / \mathrm{m})$ (b)
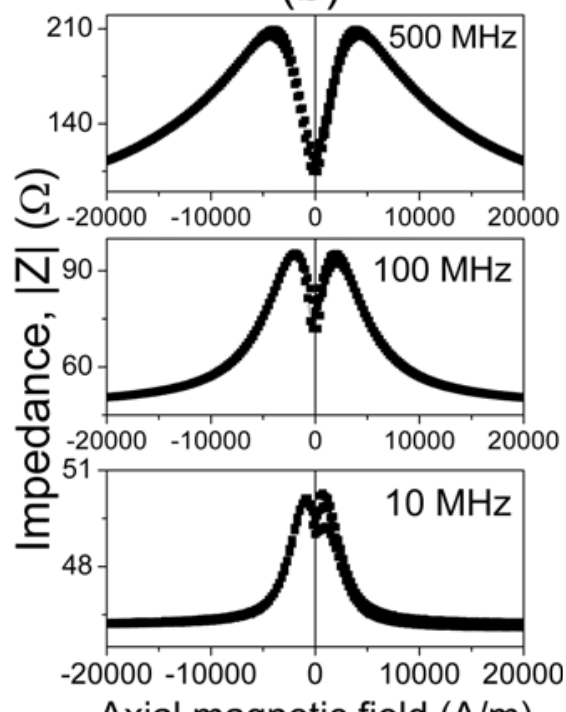

Axial magnetic field $(\mathrm{A} / \mathrm{m})$ (c)
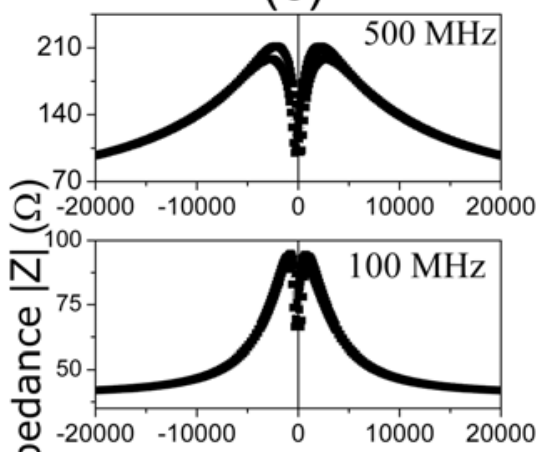

है

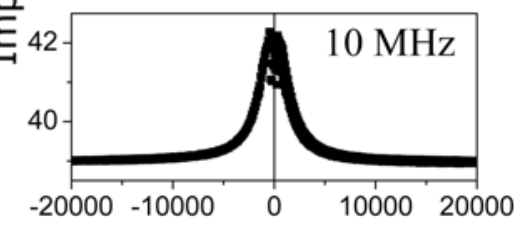

Axial magnetic field $(A / m)$

Fig. (4). $Z(H)$ dependence of $\mathrm{Fe}_{75.5} \mathrm{~B}_{13} \mathrm{Si}_{11} \mathrm{Mo}_{0.5}(\mathbf{a}), \mathrm{Fe}_{3.7} \mathrm{Co}_{69.8} \mathrm{Ni}_{1} \mathrm{Si}_{11} \mathrm{~B}_{13} \mathrm{Mo}_{1.5}(\mathbf{b})$ and $\mathrm{Co}_{77.5} \mathrm{Si}_{7.5} \mathrm{~B}_{15}(\mathbf{c})$.

Finally magnetic field dependence of the impedance has been also measured in 3 different thin glass-coated microwires in the same frequency range $(10-500 \mathrm{MHz}$ ) (see Fig. 4). At $10 \mathrm{MHz}$ the GMI of Fe-rich microwires is smaller than in cold-drawn wires, but at higher frequencies GMI effect significantly increases. The shape of the $\mathrm{Z}(\mathrm{H})$ is quite different from cold drawn wires, showing roughly only the decay with DC applied magnetic field. Small maximum can be appreciated at about $500 \mathrm{MHz}$. Co-rich microwires exhibit much higher GMI effect at all frequencies and the shape of the $\mathrm{Z}(\mathrm{H})$ dependence is typical for the materials with circular magnetic anisotropy, i.e. with the maximum at certain $d c$ axial magnetic field.

The main difference in $\mathrm{Z}(\mathrm{H})$ dependences for 3 different families of amorphous wires can be summarized as follows: i) GMI ratio decreases with frequency between 10 and 500 $\mathrm{MHz}$ in conventional wires (for Fe-rich wires this decrease follows after the first increase of $\Delta \mathrm{Z} / \mathrm{Z}_{\max }$ ), while increases in thinner wires (both cold drawn and glass coated); ii) Cold drawn wires possess considerable hysteresis on $\mathrm{Z}(\mathrm{H})$ dependences; iii) Even Fe-rich cold amorphous wires exhibit considerable GMI effect at elevated frequencies.
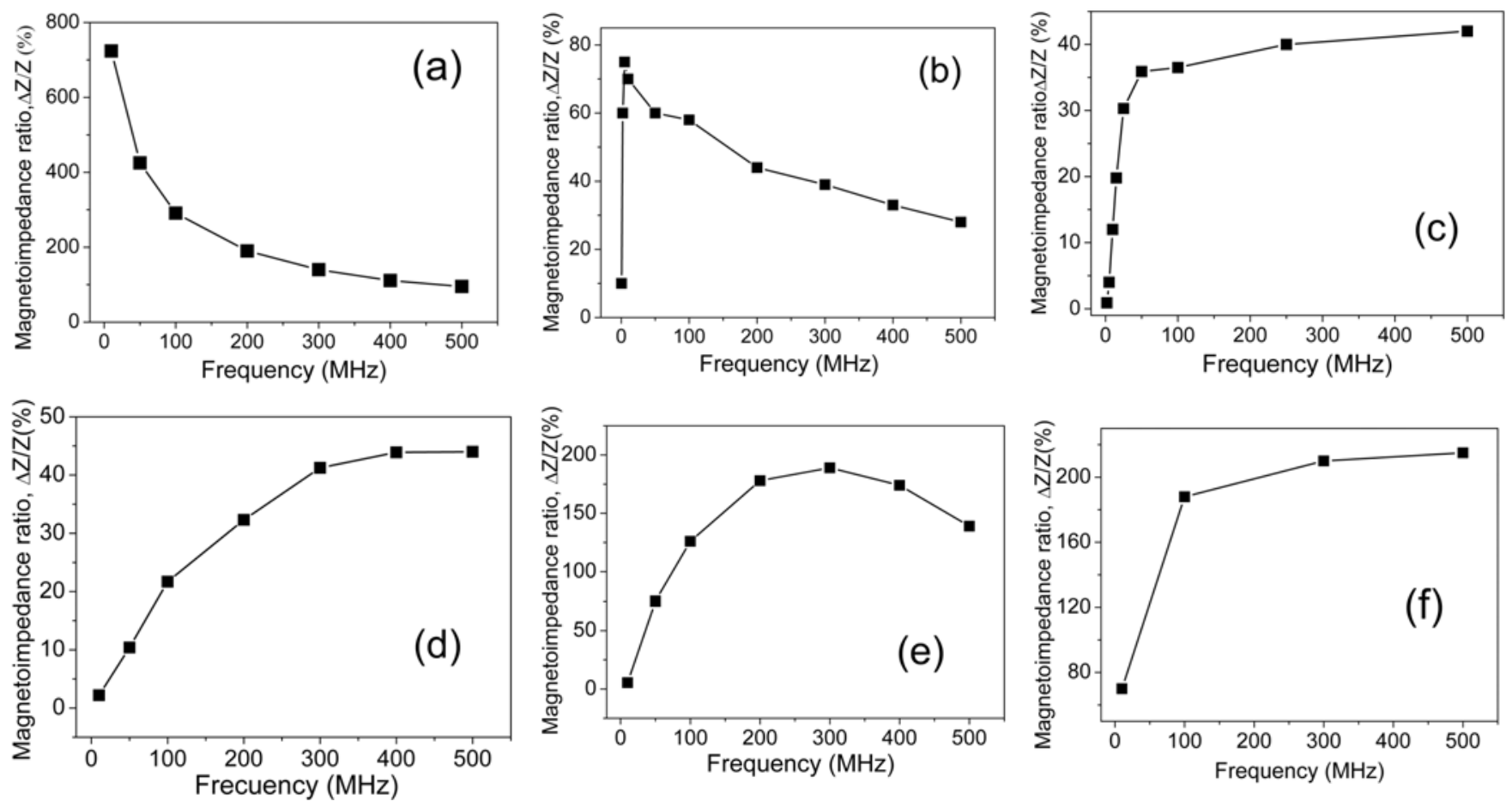

Fig. (5). $\Delta \mathrm{Z} / \mathrm{Z}_{\max }$ (f) dependence for different amorphous wires: Conventional (a)- $\left(\mathrm{Co}_{0.94} \mathrm{Fe}_{0.06}\right)_{72.5} \mathrm{Si}_{12.5} \mathrm{~B}_{15}$; and (b)- $\mathrm{Fe}_{77.5} \mathrm{~B}_{15} \mathrm{Si}_{7.5}$ wires; Cold drawn (c)- $\mathrm{Fe}_{77.5} \mathrm{~B}_{15} \mathrm{Si}_{7.5}(50 \mu \mathrm{m})$ wires and glass-coated (d)-Fe $\mathrm{Fe}_{75.5} \mathrm{~B}_{13} \mathrm{Si}_{11} \mathrm{Mo}_{0.5}$; (e)- $\mathrm{Co}_{77.5} \mathrm{Si}_{7.5} \mathrm{~B}_{15}$ and $(\mathbf{f})-\mathrm{Fe}_{3.7} \mathrm{Co}_{69.8} \mathrm{Ni}_{1} \mathrm{Si}_{11} \mathrm{~B}_{13} \mathrm{Mo}_{1.5}$ microwires. 

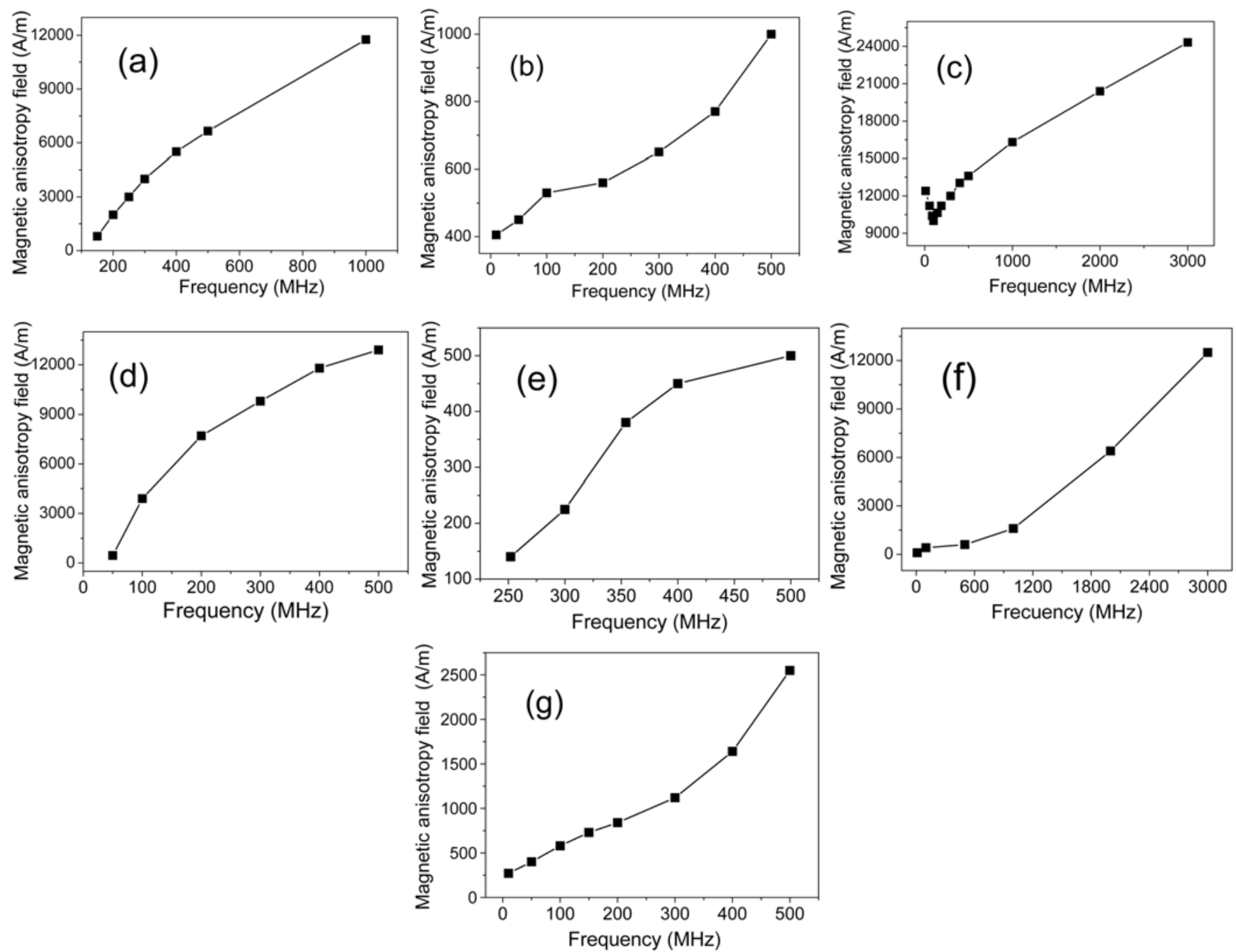

Fig. (6). $\mathrm{H}_{\mathrm{m}}$ (f) dependence in different amorphous wires: Conventional wires of (a) - $\left(\mathrm{Co}_{0.94} \mathrm{Fe}_{0.06}\right)_{72.5} \mathrm{Si}_{12.5} \mathrm{~B}_{15}$; and $(\mathbf{b})$ - $\mathrm{Fe}_{77.5} \mathrm{~B}_{15} \mathrm{Si}_{7.5}$ compositions; Cold drawn wires (c)- $\mathrm{Fe}_{77.5} \mathrm{~B}_{15} \mathrm{Si}_{7.5}$ with diameter $50 \mu \mathrm{m},(\mathbf{d})$ - $\mathrm{Fe}_{77.5} \mathrm{~B}_{15} \mathrm{Si}_{7.5}$ with diameter $20 \mu \mathrm{m}$ and glass-coated microwires of (e)- $\mathrm{Fe}_{75.5} \mathrm{~B}_{13} \mathrm{Si}_{11} \mathrm{Mo}_{0.5} ;$ (f)- $\mathrm{Co}_{77.5} \mathrm{Si}_{7.5} \mathrm{~B}_{15}$ and (g)- $\mathrm{Fe}_{3.7} \mathrm{Co}_{69.8} \mathrm{Ni}_{1} \mathrm{Si}_{11} \mathrm{~B}_{13} \mathrm{Mo}_{1.5}$ compositions.

These results are summarized in (Figs. 5 and $\mathbf{6}$ ) where $\Delta \mathrm{Z} / \mathrm{Z}_{\max }(\mathrm{f})$ and $\mathrm{H}_{\mathrm{m}}(\mathrm{f})$ dependences are shown.

A remarkable difference in magnetic field dependence of the GMI effect can be attributed to the different magnetoelastic anisotropy of these three families of the wires. Thus, as-cast conventional wires possess smallest internal stresses of the thermal origin. In the case of cold drawn wires, the additional strong stresses are arising from the cold drawn processing. These wires possess enhanced magnetic hardness, as compared to the other families of the studied wires. Therefore the magnetic anisotropy field, $\mathrm{H}_{\mathrm{m}}$, associated with the field, at which the maximum on the $\mathrm{Z}(\mathrm{H})$ dependence takes place[7], is the highest. Alternatively, glass-coated wires are the composite materials.

Consequently, the glass-coating technology gives rise to the internal stresses due to the difference in the thermal expansion coefficients of the glass coating and metallic nucleus. These differences in the fabrication technique result in the different magnetic anisotropy in the surface and in different frequency dependence of the GMI effect. On the other hand, quite unusual frequency dependence of the $\mathrm{H}_{\mathrm{m}}$ is observed in cold drawn Fe-rich wires (Fig. 6c). In fact, this is the unique wire showing non-monotonic dependence of $\mathrm{H}_{\mathrm{m}}$ (f). Such non-monotonic dependence can be attributed to the cold drawn induced magnetoelastic anisotropy in the surface layer of the wire.

\section{TAILORING OF GMI EFFECT IN THIN GLASS- COATED MICROWIRES}

\section{Effect of the Sample Composition, Heat Treatment and Geometry on the Hysteresis Loops}

Hysteresis loops of glass-coated microwires with sample composition and sample geometry as the parameters $\left(\mathrm{Co}_{69}\right.$ ${ }_{x} \mathrm{Mn}_{6+\mathrm{x}} \mathrm{Si}_{10} \mathrm{~B}_{15}, \quad \mathrm{Fe}_{74} \mathrm{~B}_{13} \mathrm{Si}_{11} \mathrm{C}_{2}$ and $\mathrm{Co}_{67} \mathrm{Fe}_{3.85} \mathrm{Ni}_{1.45} \mathrm{~B}_{11.5} \mathrm{Si}_{14.5}$ $\mathrm{Mo}_{1.7}$ ) are shown in (Fig. 1b). As can be observed, hysteresis loops are quite sensible to the fabriction parameters, chemical composition and sample geometry. While Co-rich compositions present roughly inclined hysteresis loop in asprepared state, the Fe-rich microwire exhibits a perfectly rectangular hysteresis loop.

Such strong dependence of the hysteresis loops on these parameters can be related to the magnetoelastic energy. In fact, the magnetoelastic energy is given by

$\mathrm{K}_{\mathrm{me}} \approx 3 / 2 \lambda_{\mathrm{s}} \sigma_{\mathrm{i}}$, 

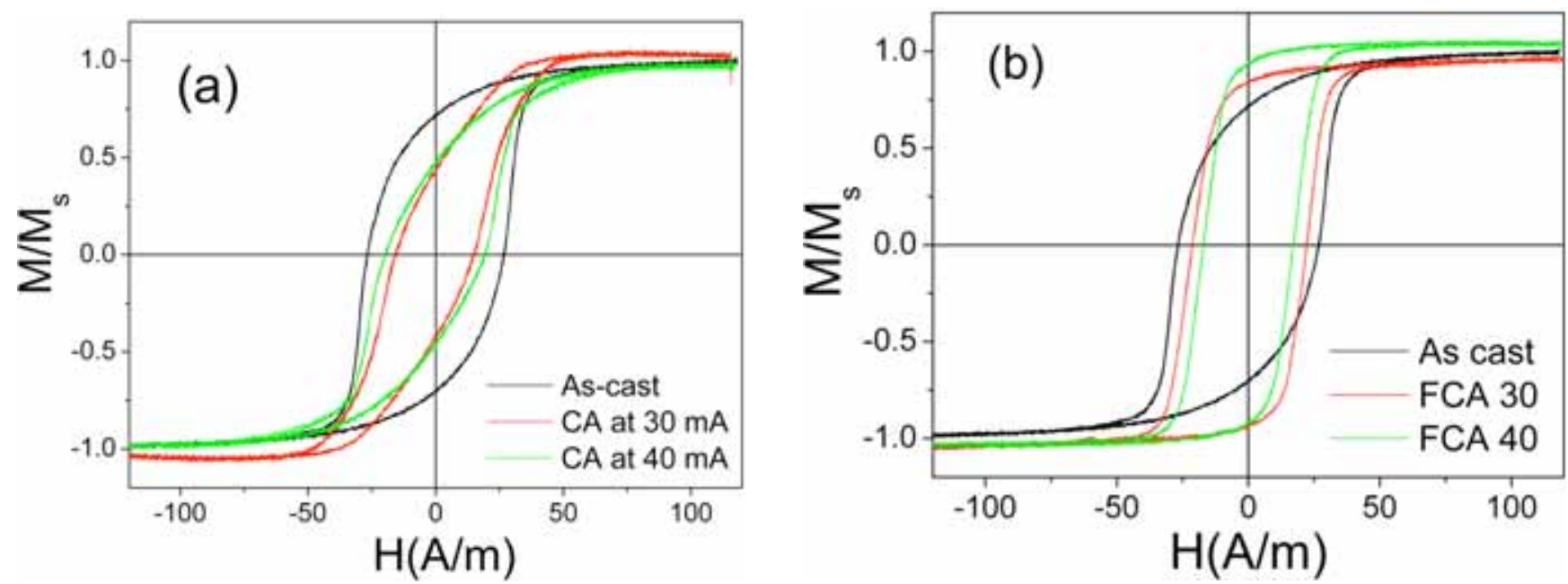

Fig. (7). Effect of CA (a) and MFA (b) treatments on bulk hysteresis loops of $\mathrm{Co}_{67} \mathrm{Fe}_{3.85} \mathrm{Ni}_{1.45} \mathrm{~B}_{11.5} \mathrm{Si}_{14.5} \mathrm{Mo}_{1.7}$ microwires.

where $\lambda_{s}$ is the saturation magnetostriction and $\sigma_{i}$ is the internal stress. The magnetostriction constant depends on the chemical composition and nearly vanishes in amorphous FeCo based alloys with $\mathrm{Co} / \mathrm{Fe} \approx 70 / 5[4,16]$. On the other hand, the estimated values of the internal stresses in these amorphous microwires arising from the difference in the thermal expansion coefficients of metallic nucleus and glass coating are of the order of 100-1000 MPa, depending strongly on the thickness of glass coating and metallic core diameter [17]. It was established that the strength of such internal stresses increases with the increasing glass coating thickness. Such large internal stresses give rise to a drastic change of the magnetoelastic energy, $K_{m e i}$, even for small changes of the glass-coating thickness at fixed metallic core diameter. Additionally, such a change of the $\rho$-ratio should be related to the change of the magnetostriction constant with applied stress [18]:

$\lambda_{\mathrm{s}}=\left(\mu_{\mathrm{o}} \mathrm{M}_{\mathrm{s}} / 3\right)\left(\mathrm{dH} \mathrm{H}_{\mathrm{k}} / \mathrm{d} \sigma\right)$,

where $\mu_{\mathrm{o}} M_{s}$ is the saturation magnetization.

These considerations allow us to predict that any method to change the internal stresses (by using thermal treatment, chemical etching, etc.) can change drastically magnetic anisotropy and consequently the hysteresis loops and the GMI behaviour.

Consequently, the hysteresis loop of $\mathrm{Co}_{69-\mathrm{x}} \mathrm{Mn}_{6+\mathrm{x}} \mathrm{Si}_{10} \mathrm{~B}_{15}$ $(\mathrm{x}=0.5)$ has been changed after conventional annealing (CA) or under magnetic field annealing (MFA) treatments (see Fig. 7).

In the case of MFA, the external axial magnetic field applied during the MFA treatment induces axial magnetic anisotropy, as can be appreciated from Fig. (7b).

It is known that the strength of the internal stresses, $\sigma$, is related to the glass coating thickness through the difference in the thermal expansion coefficients of metallic nucleus and outer glass coating solidifying simultaneously [4]. The effect of the ratio, $\rho$, between the inner metallic nucleus, $d$, and the total microwire diameter, $\mathrm{D}$, on the hysteresis loops of nearly-zero magnetostrictive $\mathrm{Co}_{67} \mathrm{Fe}_{3.85} \mathrm{Ni}_{1.45} \mathrm{~B}_{11.5} \mathrm{Si}_{14.5} \mathrm{Mo}_{1.7}$ microwires is shown in Fig. (8).

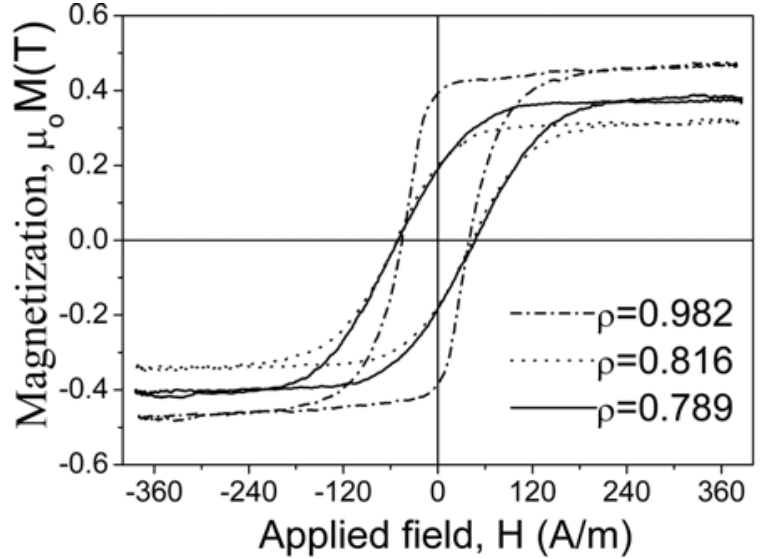

Fig. (8). Effect of the samples geometry on the hysteresis loops of Co-rich microwires with vanishing magnetostriction constant.

Until now it was assumed that the Fe-rich microwires always present rectangular hysteresis loop associated with the strong axial magnetic anisotropy induced by residual stresses of mostly tensile origin [4]. Generally the conventional annealing of Fe-rich microwires does not affect the character of the hysteresis loops, and slightly change the coercive force. As an example, the effect of the heat treatment performed at $T_{a n n}=400^{\circ} \mathrm{C}$ in $\mathrm{Fe}_{74} \mathrm{~B}_{13} \mathrm{Si}_{11} \mathrm{C}_{2}$ is illustrated in Fig. (9a). Some decrease of $H_{c}$ has been observed while the squared character of the hysteresis loop remains unchanged. On the other hand, it was recently found that the stress annealing (SA) performed at the same annealing conditions $\left(T_{a n n}=400^{\circ} \mathrm{C}\right)$ but under applied stress, $\sigma=458 \mathrm{MPa}$, results in drastic changes of the hysteresis loop (see Fig. 9), which becomes inclined with a magnetic anisotropy field of about $1000 \mathrm{~A} / \mathrm{m}$.

A transverse magnetic anisotropy induced by the SA allows us to predict the existence of the magneto impedance effect in such samples.

The above-mentioned results allow us to assume that there are a few factors that can affect the GMI behaviour of the glass coated microwires such as
a) Metallic nucleus chemical composition,
b) Samples geometry, and
c) Thermal treatments. 

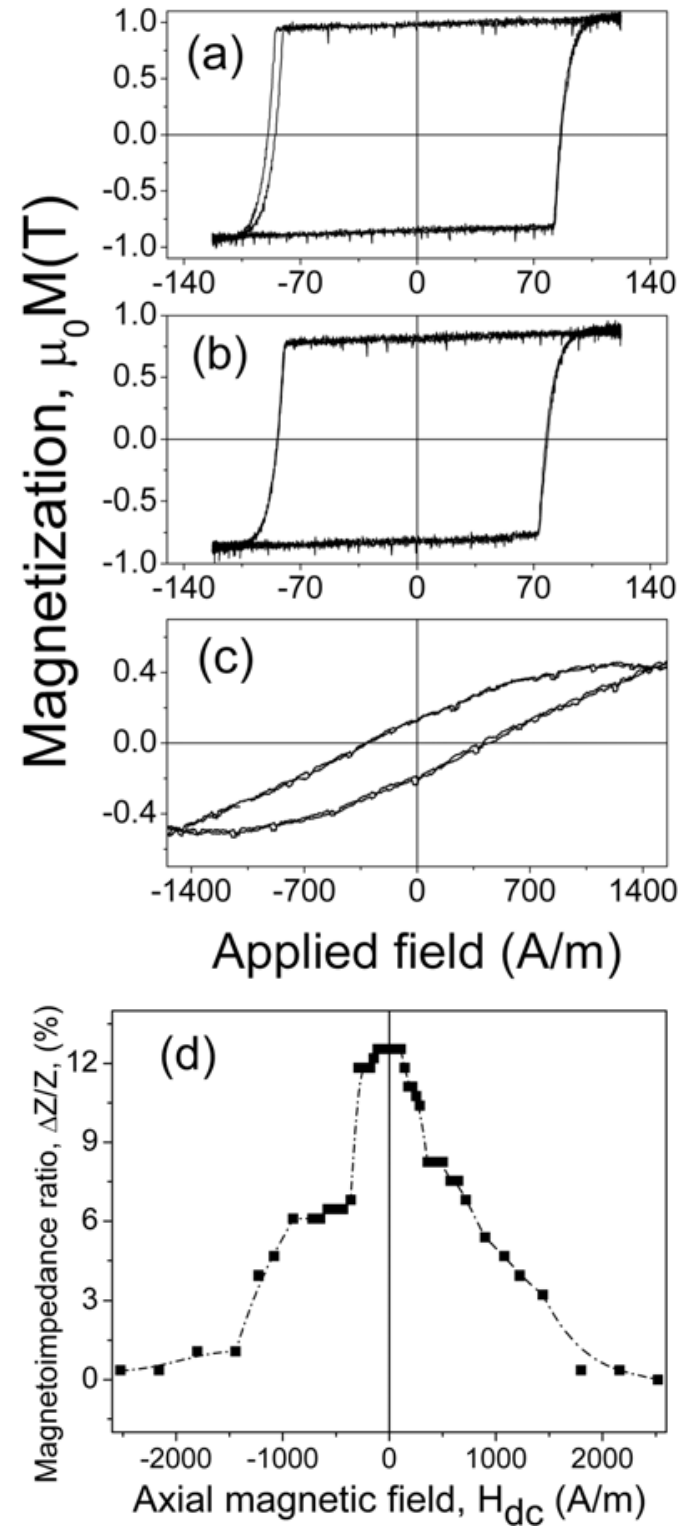

Fig. (9). Bulk hysteresis loops of $\mathrm{Fe}_{74} \mathrm{~B}_{13} \mathrm{Si}_{11} \mathrm{C}_{2}$ microwire asprepared (a), furnace annealed at $T_{a n n}=400^{\circ} \mathrm{C}$ (b) and stress annealed at $T_{a n n}=400^{\circ} \mathrm{C}$ (c) and GMI effect induced by stress annealing at $T_{a n n}=400^{\circ} \mathrm{C}(\mathbf{d})$.

\section{Tailoring of the GMI Effect}

The strongest GMI effect with clear influence of the sample geometry ( $\rho$ ratio) on GMI curves has been observed in $\mathrm{Co}_{67} \mathrm{Fe}_{3.85} \mathrm{Ni}_{1.45} \mathrm{~B}_{11.5} \mathrm{Si}_{14.5} \mathrm{Mo}_{1.7}$ microwire (see Fig. 10).

Generally, as has been predicted, the $\mathrm{Co}_{67} \mathrm{Fe}_{3.85} \mathrm{Ni}_{1.45}$ $\mathrm{B}_{11.5} \mathrm{Si}_{14.5} \mathrm{Mo}_{1.7}$ sample geometry strongly affects the dependence of the GMI ratio on DC axial magnetic field. As can be observed from Fig. (10), the field $H_{m}$, corresponding to the maximum of the GMI ratio, increases and $(\Delta Z / Z)_{\max }$ decreases with the $\rho$-ratio.

It means that the internal stresses, arising from the difference between the thermal expansion coefficients of the metallic core and glass coating, strongly affect the aforementioned properties.

Indeed, the axial field dependence of $(\Delta Z / Z)$ measured in $\mathrm{Co}_{69-\mathrm{x}} \mathrm{Mn}_{6+\mathrm{x}} \mathrm{Si}_{10} \mathrm{~B}_{15}(\mathrm{x}=0.5)$ microwire under applied tensile stresses, $\sigma$, ranging from 0 to $132 \mathrm{MPa}(0-2.9 \mathrm{~g}$ of mechanical loading) and at $f=10 \mathrm{MHz}$ and $I=1 \mathrm{~mA}$ is shown in Fig. (11). In the unstressed state there is a maximum in $(\Delta Z / Z)_{m}$ for a value of around $130 \mathrm{~A} / \mathrm{m}$ of axial applied field. This maximum displaces towards larger applied fields and the value of $(\Delta Z / Z)_{m}$ has a non-monotonic dependence on $\sigma$ with a broad maximum at around $60 \mathrm{MPa}$. The maximum GMI ratio, $(\Delta Z / Z)_{m}$, reaches $130 \%$ at such tension.

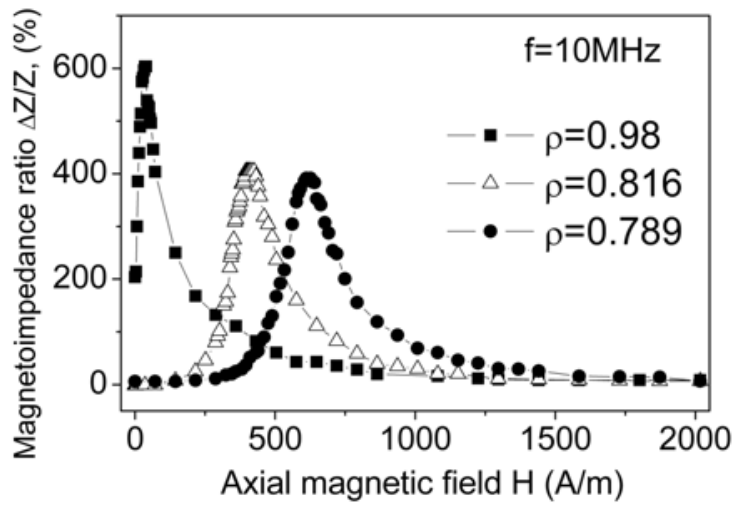

Fig. (10). Axial field dependence of $\Delta \mathrm{Z} / \mathrm{Z}$ at $\mathrm{f}=10 \mathrm{MHz}$ and $I=0.75$ $\mathrm{mA}$ in microwire with $\rho$ as a parameter.

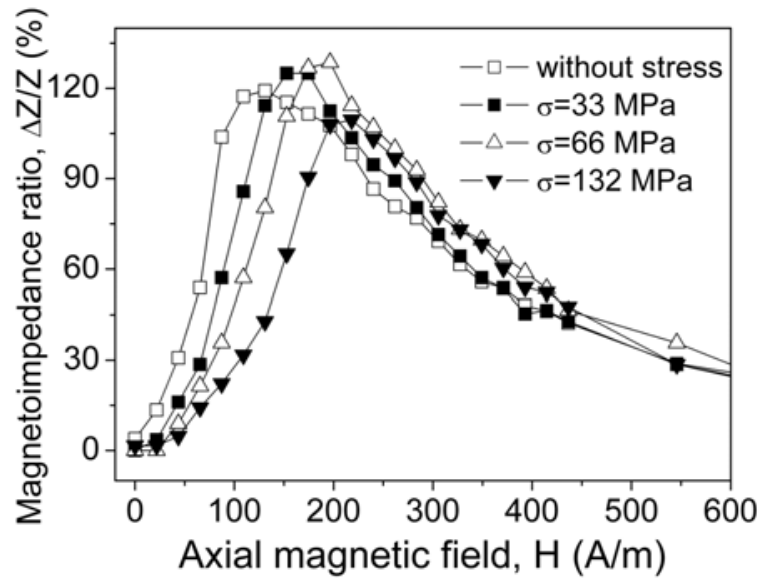

Fig. (11). Effect of applied stresses on $\Delta \mathrm{Z} / \mathrm{Z}$ ratio of $\mathrm{Co}_{68.5} \mathrm{Mn}_{6.5} \mathrm{Si}_{10} \mathrm{~B}_{15}$ amorphous microwire.

Therefore, the relaxation of such internal stresses by means of thermal treatment should drastically change both the soft magnetic behaviour and $\Delta Z / Z(H)$ dependence. This challenge is of special importance since the fabrication of the microwires with the glass coating thickness of about $0.2 \mu \mathrm{m}$ exhibiting very large (600\%) GMI ratios is a difficult task. This is why an identification of the processing procedure, which permits to improve the GMI effect of the glass-coated microwires, is very important from the viewpoint of applications. The effect of Joule heat treatment was performed using the sample $\mathrm{Co}_{67} \mathrm{Fe}_{3.85} \mathrm{Ni}_{1.45} \mathrm{~B}_{11.5} \mathrm{Si}_{14.5} \mathrm{Mo}_{1.7}$.

As expected, the performed Joule heating strongly affects the $\Delta Z / Z(H)$ dependence. Fig. (12) shows this dependence measured for as-prepared and annealed $\mathrm{Co}_{67} \mathrm{Fe}_{3.85} \mathrm{Ni}_{1.45} \mathrm{~B}_{11.5}$ $\mathrm{Si}_{14.5} \mathrm{Mo}_{1.7}$ (CA treatment) samples with the frequency, $f$, as a parameter. It is well recognized that the maximum value of the GMI ratio, $\Delta Z / Z_{\max }$, increases with $f$ as well as after CA treatment. Besides, the value of the axial $D C$-field, $H_{m}$, corresponding to the maximum of the GMI ratio, increases also as a result of the Joule heating. 


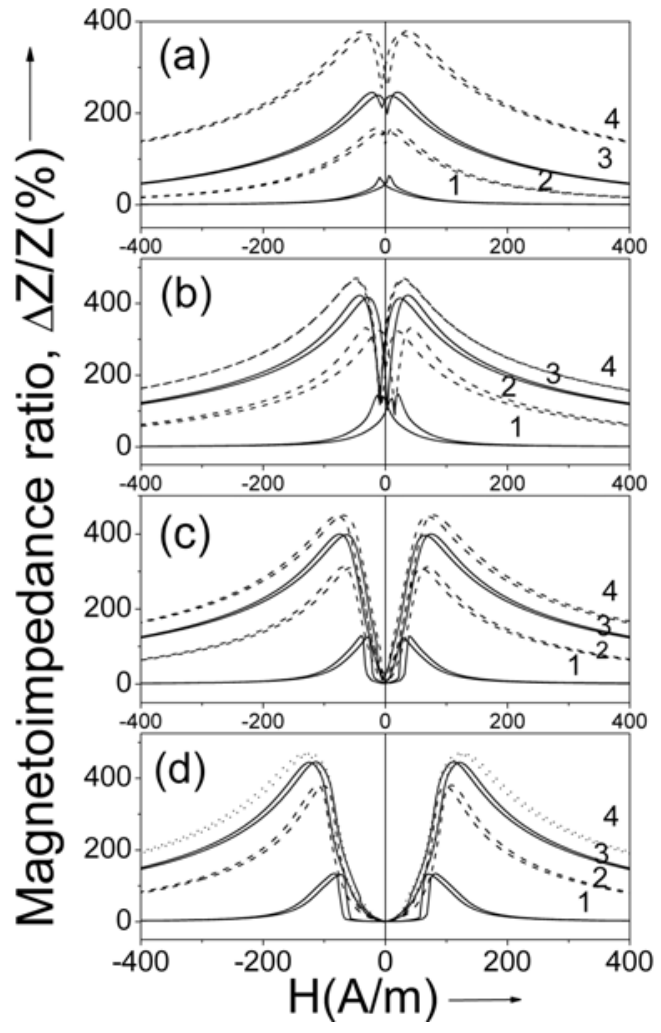

Fig. (12). $\Delta Z / Z(H)$ dependence measured in as-prepared microwire at $I=1 \mathrm{~mA}$ (a) subjected to CA annealing at $30 \mathrm{~mA}$ for 2 minutes (b) at $40 \mathrm{~mA}$ for 2 minutes (c) and at $40 \mathrm{~mA}$ for 10 minutes for $\mathrm{f}=1 \mathrm{MHz}$ (1), $10 \mathrm{MHz}$ (2), $20 \mathrm{MHz}$ (3)and $30 \mathrm{MHz}$ (4).

In order to better illustrate the only effect of the Joule heating, the $\Delta Z / Z(H)$ dependence has been measured under the same conditions, i.e. at the fixed frequency and driving current amplitude with a sole variation of the Joule heating conditions. The dependence is presented in Fig. (13a) (annealing current $30 \mathrm{~mA}$ ) and in Fig. (13b) (40 mA).

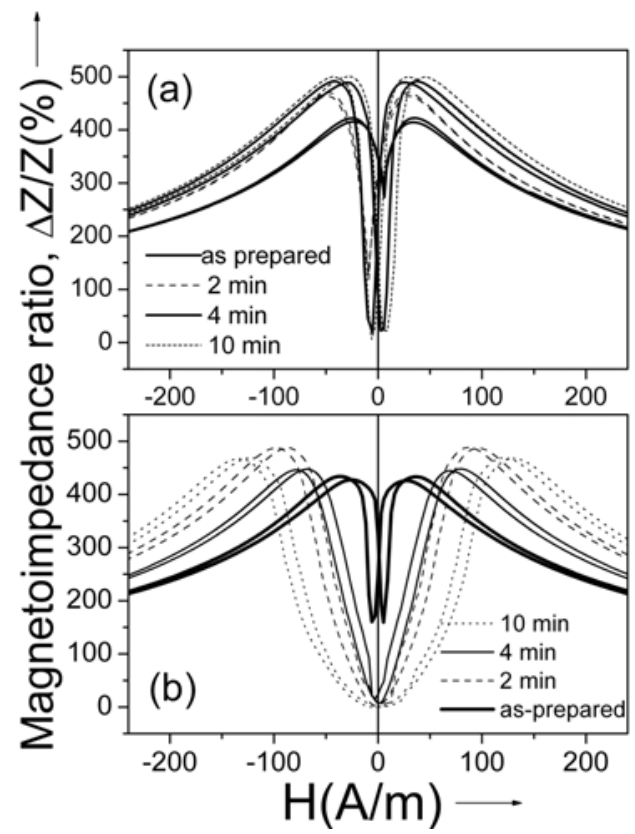

Fig. (13). $\Delta Z / Z(H)$ dependence measured at $f=30 \mathrm{MHz}$ and $I=1 \mathrm{~mA}$ in microwire subjected to CA annealing at $30 \mathrm{~mA}$ (a) and at $40 \mathrm{~mA}$ (b).
Changes induced by the thermal treatment according to Eq. (5) should be attributed to the changes of the magnetic anisotropy field under annealing. Thus general decrease of the $H_{m}$ value with annealing time observed for the magnetic field annealing treatment (see Fig. 13b), should be related to the induction of the axial magnetic anisotropy, while CA annealing results in an increase in the $H_{m}$ value with annealing time.

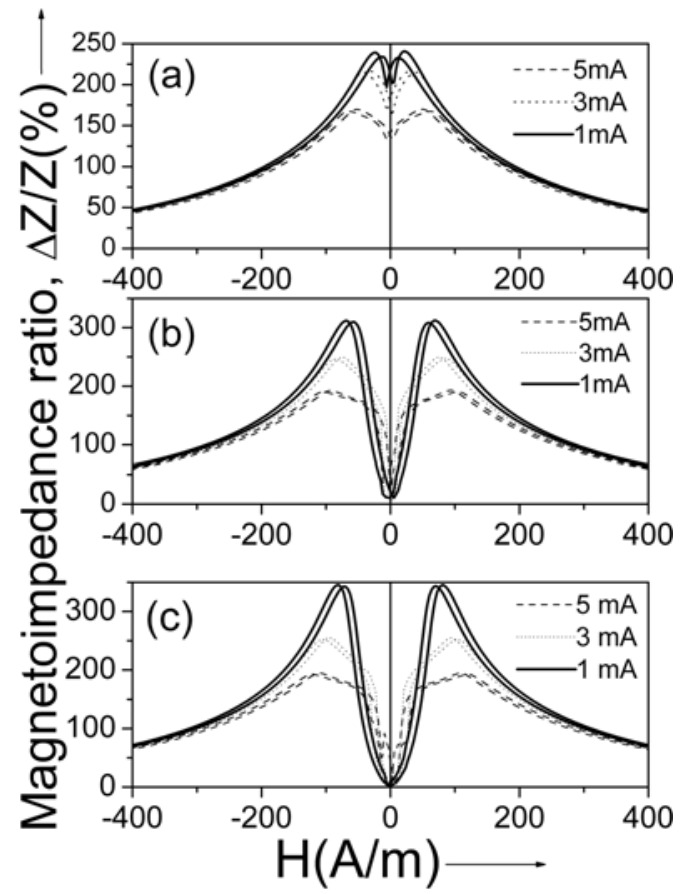

Fig. (14). Effect of driving current amplitude on $\Delta Z / Z(H)$ dependence measured at $f=10 \mathrm{MHz}$ in as-prepared (a), subjected to CA annealing at $40 \mathrm{~mA}$ for $2 \mathrm{~min}$ (b) and at $40 \mathrm{~mA}$ for $4 \mathrm{~min}$ (c) $\mathrm{mi}-$ crowires.

Taking into account the phenomenologically found [18] stress dependence of the magnetostriction

$\lambda_{\sigma}(\sigma)=\lambda_{\mathrm{s}}(0)-\mathrm{A} \sigma$

where $\lambda_{\mathrm{s}}(0)$ is the saturation magnetostriction constant without applied stresses and $\mathrm{A}$ is the positive coefficient of the order of $10^{-10} \mathrm{MPa}$, one can assume that stress relaxation should give rise to a decrease of the $H_{m}$ value. Such contradiction can be attributed to the induction of the circular magnetic anisotropy after the $C A$ due to the effect of the circular magnetic field created by the $D C$ current during the Joule heating.

Another important parameter affecting the $\Delta Z / Z(H)$ dependence is the driving $A C$-current amplitude. Fig. (14) shows the effect of the driving current amplitude on the GMI behaviour of the as-prepared and annealed micro-wires. There are a few parameters that can be used to tailor the GMI effect of glass coated microwires, such as time, $t_{a n n}, D C$ current, $I$, of Joule heating, frequency, $f$, and driving $A C$ current amplitude, $I$, during the measurements of the GMI effect. The effect of all these parameters on the maximum GMI ratio, $\Delta Z / Z_{\max }$, is summarized in the Fig. (15).

It is worthwhile to notice that not only the maximum of the GMI ratio, $\Delta Z / Z_{\max }$, but also the shape of $\Delta Z / Z(H)$ dependence change under the effect of the current annealing. In 
particular, the field corresponding to the maximum of the GMI ratio, $H_{m}$, depends on the current annealing conditions. Fig. (16) summarizes the effect of all the mentioned parameters on $H_{m}$.

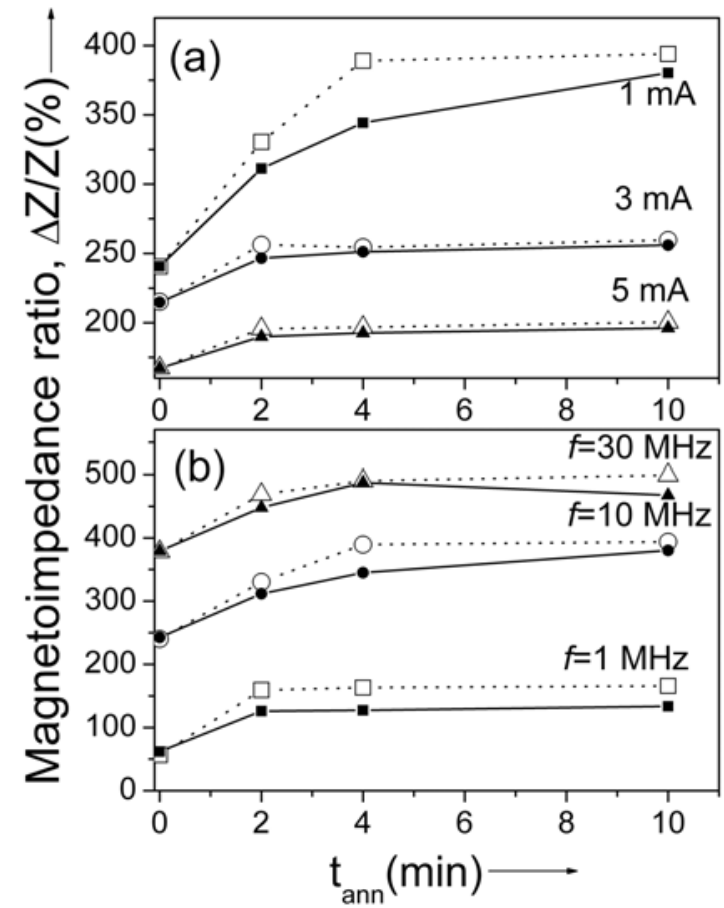

Fig. (15). Effect of driving current amplitude (a) on $\Delta Z / Z_{\max }$ measured in microwires annealed (CA treatment) at $30 \mathrm{~mA}$ (dot lines) and at $40 \mathrm{~mA}$ (solid lines) and effect of frequency (b) on $\Delta Z / Z_{\max }$ measured at $I=1 \mathrm{~mA}$ in microwires annealed (CA treatment ) at 30 $\mathrm{mA}$ (dot lines) and at $40 \mathrm{~mA}$ (solid lines).

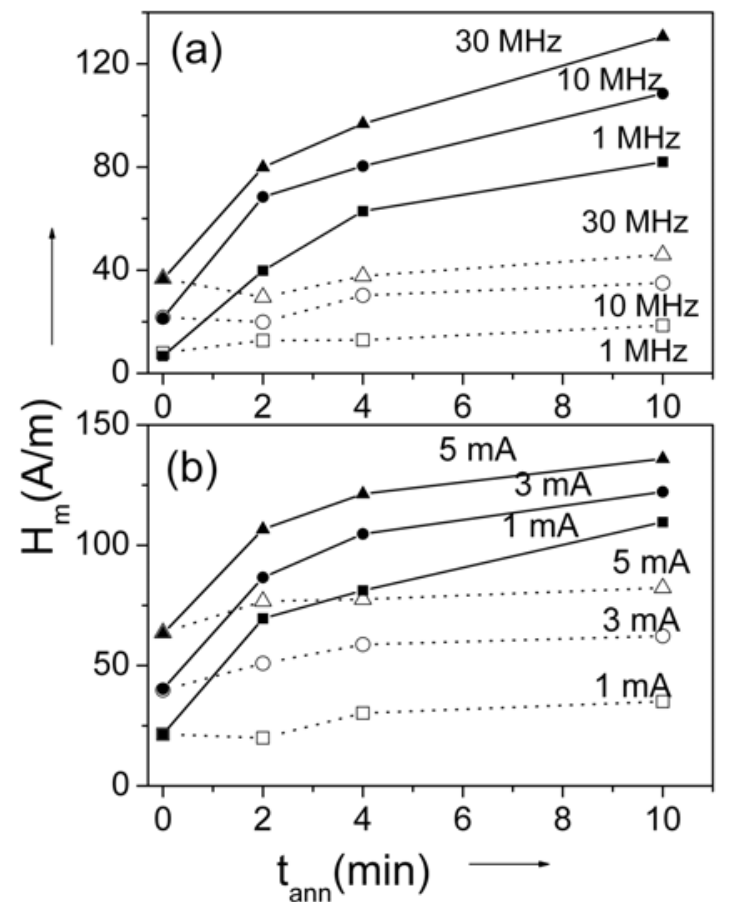

Fig. (16). Effect of frequency (a) on $H_{m}$ measured at $10 \mathrm{MHz}$ in microwires annealed (CA treatment ) at $30 \mathrm{~mA}$ (dot lines) and at 40 $\mathrm{mA}$ (solid lines) and effect of driving ac current amplitude (b) measured in the same microwires at $I=1 \mathrm{~mA}$ annealed (CA treatment ) at $30 \mathrm{~mA}$ (dot lines) and at $40 \mathrm{~mA}$ (solid lines).

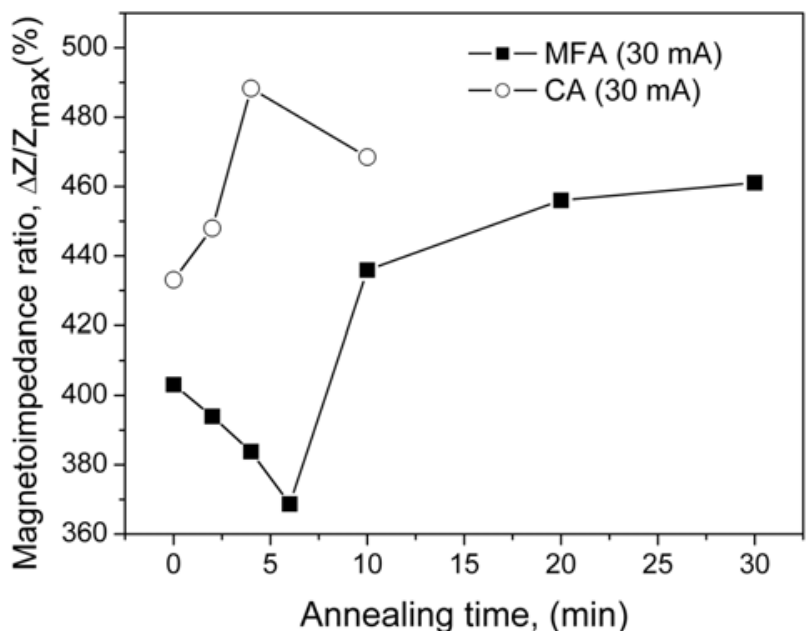

Fig. (17). Effect of Joule heating without magnetic field (CA) and the Joule heating under axial magnetic field (MFA) on $\Delta Z / Z_{\max }$ and $H_{m}$ of studied microwires measured at $30 \mathrm{MHz}$ and $1 \mathrm{~mA}$.

As shown in Fig. (7), the MFA treatment of $\mathrm{Co}_{67} \mathrm{Fe}_{3.85} \mathrm{Ni}_{1.45} \mathrm{~B}_{11.5} \mathrm{Si}_{14.5} \mathrm{Mo}_{1.7}$ microwire induces axial magnetization axis. Taking into account that CA and MFA treatments induce significant changes in the hysteresis loops of $\mathrm{Co}_{67} \mathrm{Fe}_{3.85} \mathrm{Ni}_{1.45} \mathrm{~B}_{11.5} \mathrm{Si}_{14.5} \mathrm{Mo}_{1.7}$ microwires, considerable changes of the GMI ratio dependence on the axial magnetic field have been observed. Thus, both $\Delta Z / Z_{\max }$, and $H_{m}$ after MFA treatment change through different ways owing to such induced magnetic anisotropy (see Fig. 17).
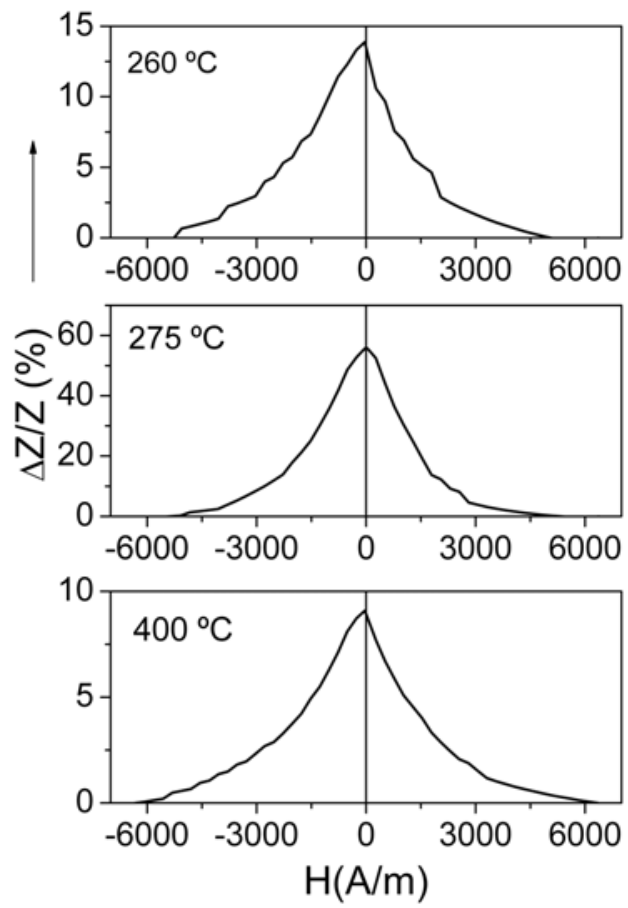

Fig. (18). $\Delta Z / Z(H)$ dependences measured in $\mathrm{SA} \mathrm{Fe}_{74} \mathrm{~B}_{13} \mathrm{Si}_{11} \mathrm{C}_{2}$ microwire.

It is worthwhile to mention that, as has been predicted, even Fe-rich sample annealed under special conditions allowing to exhibit small transverse magnetic anisotropy can exhibit GMI effect. Thus, significant GMI effect (about $60 \%$ ) has been observed in the $\mathrm{SA}$ annealed $\mathrm{Fe}_{74} \mathrm{~B}_{13} \mathrm{Si}_{11} \mathrm{C}_{2}$ microwire (see Fig. 18). Besides, this GMI effect is strongly dependent on annealing temperature (Fig. 18) [13]. It is 

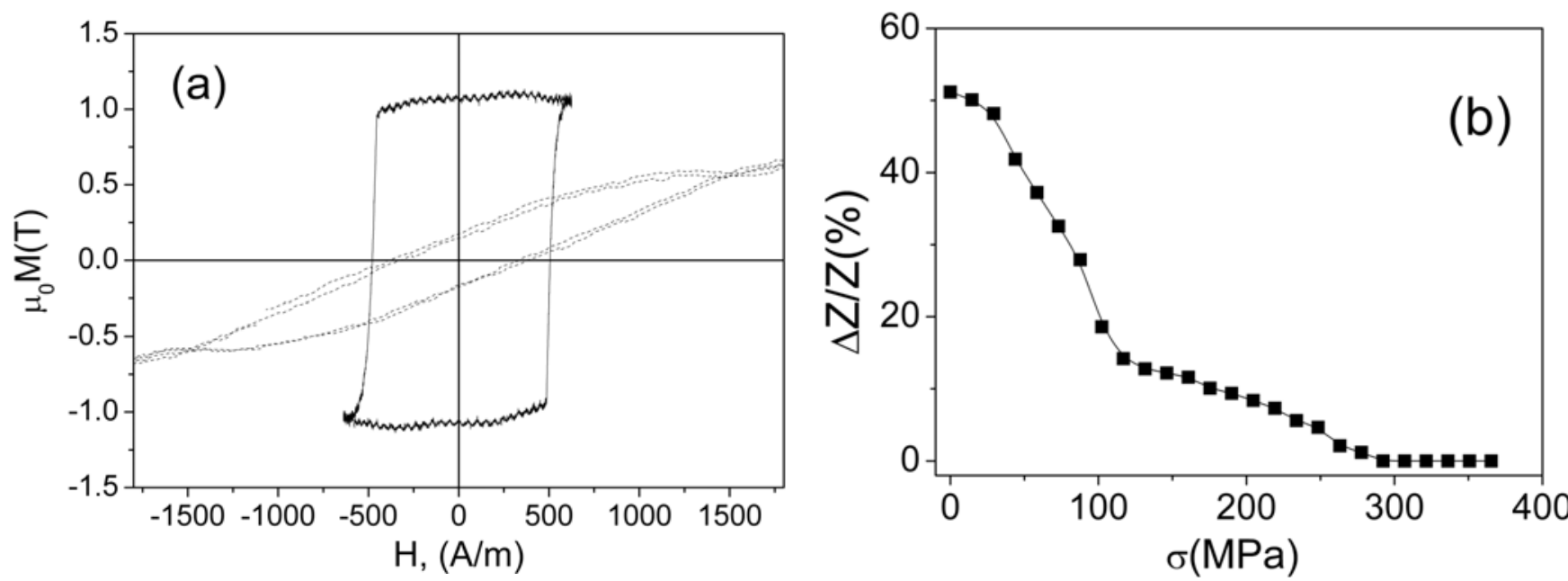

Fig. (19). (a) - hysteresis loop of $\mathrm{SA} \mathrm{Fe}_{74} \mathrm{~B}_{13} \mathrm{Si}_{11} \mathrm{C}_{2}$ glass-coated microwire measured under applied stress of $500 \mathrm{MPa}$ (hysteresis loop of $\mathrm{Fe}_{74} \mathrm{~B}_{13} \mathrm{Si}_{11} \mathrm{C}_{2}$ subjected to $\mathrm{SA}$ without stress has been shown for the comparison by dashed line), (b) - stress impedance effect of annealing under stress $(468 \mathrm{MPa})$ at $400^{\circ} \mathrm{C}$ for $t=170 \mathrm{~s} \mathrm{Fe}_{74} \mathrm{~B}_{13} \mathrm{Si}_{11} \mathrm{C}_{2}$ glass-coated microwire measured at $10 \mathrm{MHz}$ for the driving current amplitude of 2 $\mathrm{mA}$.

worth mentioning that such stress annealed Fe-rich samples exhibiting GMI effect exhibit even more unusual feature, such as elevated stress sensitivity of both hysteresis loops and GMI, as it is shown in Fig. (19). Such behavior makes them quite suitable for designing of stress sensitive elements and sensor [13].

\section{Development of Extremely thin Microwires with GMI Effect}

As it was mentioned above, the GMI effect is related intrinsically to the hysteresis loops of the samples and consequently the shape of $\Delta Z / Z(H)$ dependence is determined by the magnetic anisotropy. Therefore in order to achieve high enough GMI effect it is important to select right chemical composition with vanishing magnetostriction constant, minimizing by this way the strong effect of the internal stress. Based on previous knowledge of the effect of chemical composition on soft magnetic behaviour of amorphous alloys [14], a $\mathrm{Co}_{67,05} \mathrm{Fe}_{3,84} \mathrm{Ni}_{1,44} \mathrm{Si}_{14,47} \mathrm{~B}_{11,51} \mathrm{Mo}_{1,69}$ composition is selected to fabricate thin microwires. The hysteresis loop of the microwire with inner diameter of $8.5 \mu \mathrm{m}$ is presented in Fig. (20). As can be noted from Fig. (20), excellent magnetic softness with coercivity of the order of $4 \mathrm{~A} / \mathrm{m}$ has been achieved in this microwire in spite of its reduced diameter.

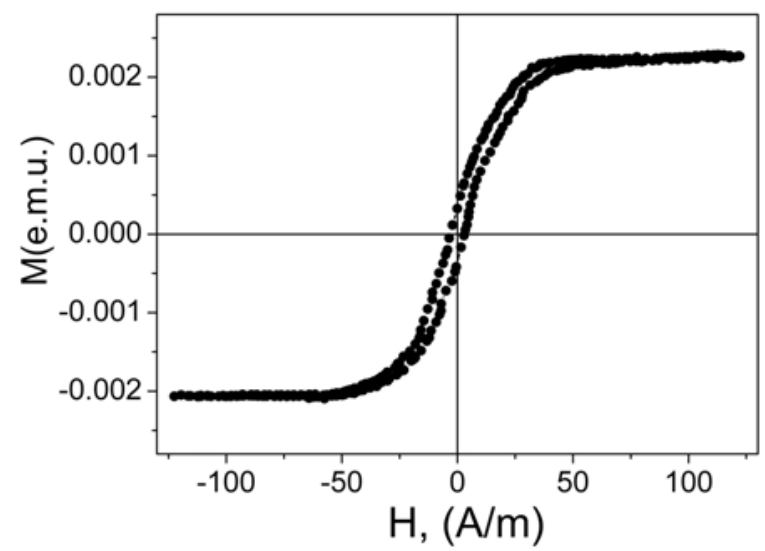

Fig. (20). Hysteresis loops of $\mathrm{Co}_{67,05} \mathrm{Fe}_{3,84} \mathrm{Ni}_{1,44} \mathrm{Si}_{14,47} \mathrm{~B}_{11,51} \mathrm{Mo}_{1,69}$ microwire.

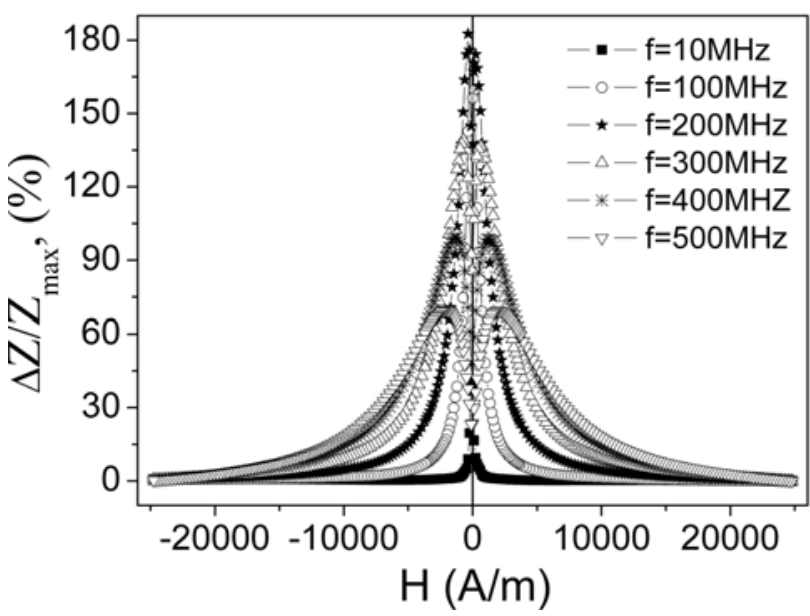

Fig. (21). GMI ratio of as-prepared microwire $\mathrm{Co}_{67.05} \mathrm{Fe}_{3,84} \mathrm{Ni}_{1,44}$ $\mathrm{Si}_{14,47} \mathrm{~B}_{11,51} \mathrm{Mo}_{1,69}$ measured at frequencies up to $500 \mathrm{MHz}$.

The GMI effect of as-prepared $\mathrm{Co}_{67.05} \mathrm{Fe}_{3,84} \mathrm{Ni}_{1,44} \mathrm{Si}_{14,47}$ $\mathrm{B}_{11,51} \mathrm{Mo}_{1,69}$ measured at frequencies, $f$, up to $500 \mathrm{MHz}$ is shown in Fig. (21). As can be observed, considerable GMI ratio is achieved at higher frequencies, although at conventional frequency $f=10 \mathrm{MHz}$, the GMI ratio is about $60 \%$. The shape of the $D C$ magnetic field dependence of the GMI ratio is typical for the samples with small and negative magnetostriction constant with circular magnetic anisotropy, i.e. with a maximum at certain $D C$ axial magnetic field, $\mathrm{H}_{\mathrm{m}}$. The maximum value of the GMI ratio, $\Delta \mathrm{Z} / \mathrm{Z}_{\max }$, is achieved to be about $180 \%$ at about $200 \mathrm{MHz}$. Frequency dependence of the $\Delta \mathrm{Z} / \mathrm{Z}_{\max }$ is shown in Fig. (22).

As it was shown, imaginary part of the impedance is quite useful for the use in magnetic sensors. Fig. (23) shows the imaginary part the impedance, $\mathrm{X}$, measured at different frequencies.

Regarding the observed experimental results, it is worth underlining high enough GMI effect in such thin microwires. Usually high GMI effect has been observed in thick enough wires or glass-coated microwires. Besides, in the case of glass-coated microwires the glass coating thickness was 
small enough. Conventional interpretation of the GMI effect deals with the high enough circumferential magnetic permeability associated with enhanced magnetic softness in nearlyzero magnetostrictive wires. Such enhanced circumferential magnetic permeability is closely related to particular domain structure of the cylindrical magnetic conductor with circular magnetic domains in the outer shell. Appearance of such circular domains in thin glass-coated microwires has been theoretically predicted in thick enough microwires $[15,16]$ and the single domain structure was assumed for the wires below some critical thickness. Such critical diameter is predicted to be of order of a few $\mu \mathrm{m}$. On the other hand, with the decreasing glass-coated microwires diameter the strength of the internal stresses drastically increases [17-19], giving rise to the growth of the magnetoelastic energy. Therefore, it is not an easy task to produce magnetically soft thin glasscoated microwires, and the nearly-zero magnetostrictive composition should be selected with a high precision.

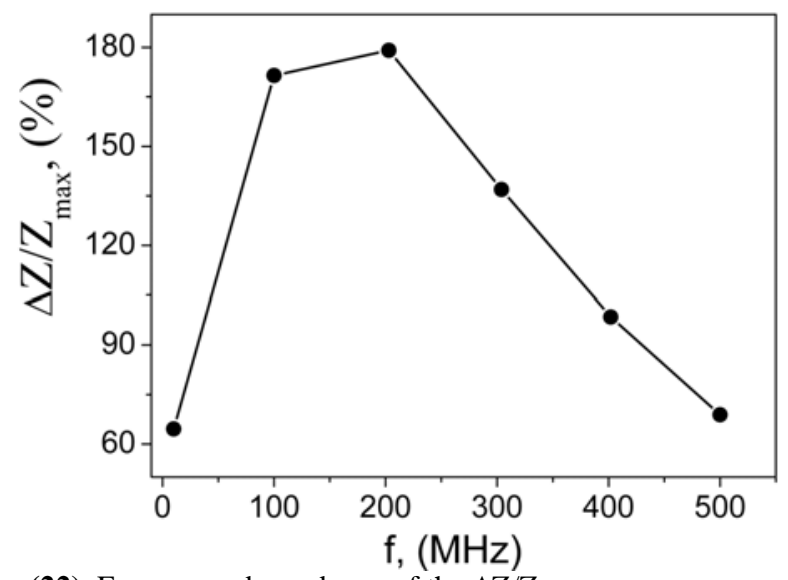

Fig. (22). Frequency dependence of the $\Delta \mathrm{Z} / \mathrm{Z}_{\max }$.

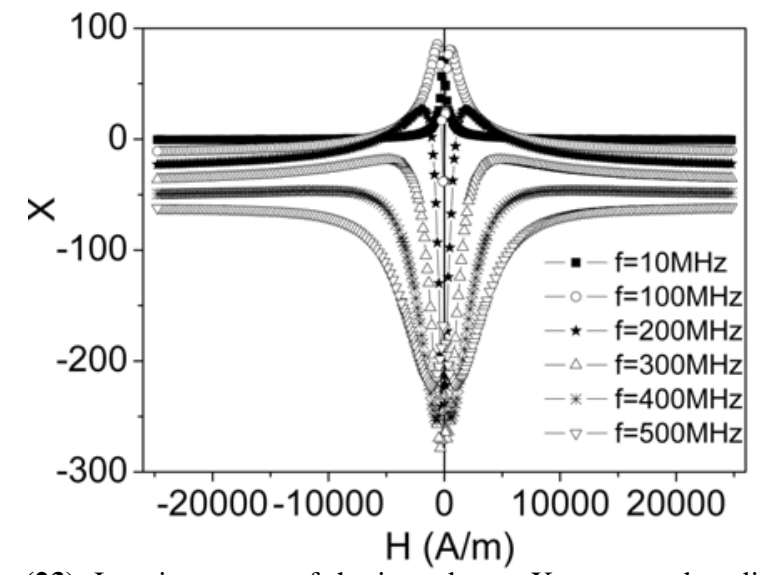

Fig. (23). Imaginary part of the impedance, $X$, measured at different frequencies.

Resuming, the comparative study of 3 different families of amorphous wires: conventional cast amorphous wires, cold-drawn wires and glass coated wires allows us to conclude that from the point of view of the tendency of miniaturization of magnetic elements the glass-coated wires are the most promising family of these kind of materials. On the other hand their composite origin and the additional magnetoelastic energy related with the presence of the glass coating require more attention to their post fabrication processing, i.e. special thermal treatment, precise control of their geome- try, chemical composition of the metallic nucleus etc. From the point of view of magnetic properties, excellent magnetic softness can be achieved in these glass-coated micwrowires after rigorous control of their parameters (geometry, chemical composition etc) and using post fabrication processing of such materials.

\section{CONCLUSIONS}

The following conclusions can be drawn: the GMI effect of 3 different families of Fe-rich and Co-rich amorphous wires has been studied at frequencies between 10 and 500 MHz. A remarkable difference in magnetic field dependence of the GMI effect can be attributed to the different magnetoelastic anisotropy of these three families of the wires.

Thinnest amorphous wires can be produced by the Taylor-Ulitovski technique. Such microwires exhibit extremely good magnetic properties that can be tailored by an appropriate selection of the metallic nucleus diameter, glass-coating thickness and chemical composition of the metallic nucleus and even by the heat treatment under magnetic field or without it. There are a number of interesting effects, such as induction of the small transversal anisotropy in Fe-rich microwires allowing to create extremely tress sensitive elements.

\section{REFERENCES}

[1] Panina LV, Mohri K. Magneto-impedance effect in amorphous wires. Appl Phys Lett 1994; 65: 1189-1191.

[2] Beach RS, Bertowitz AE. Giant magnetic field dependent impedance of amorphous FeCoSiB wire. Appl Phys Lett 1994; (64): 3652-54.

[3] Kanno T, Mohri K, Yagi T, Uchiyama T, Shen LP. Amorphous wire MI micro sensor using C-MOS IC multivibrator IEEE Trans Magn 1997; 33(5-1): 3358-60

[4] Zhukov A, González J, Vázquez M, Larin V, Torcunov A. Nanocrystalline and Amorphous Magnetic Microwires Enciclopedia of Nanoscience and Nanotechnology, Chapter 62, Ed. H.S. Nalwa, American Scientific Publishers 2004: 23.

[5] Usov NA, Antonov AS, Lagar kov AN. Theory of giant magnetoimpedance effect in amorphous wires with different types of magnetic anisotropy J Magn Magn Mat 1998; 185: 159-173.

[6] Makhnovskiy DP, Panina LV, Mapps D. Field-dependent surface impedance tensor in amorphous wires with two types of magnetic anisotropy: Helical and circumferential. J Phys Rev B 2001; 63: 1444241-17.

[7] Zhukova VA, Chizhik AB, Gonzalez J, et al. Effect of annealing under torsion stress on the field dependence of the impedance tensor in amorphous wires. J Magn Magn Mat 2002; (249): 324-29.

[8] Yoshinaga T, Furukawa S, Mohri K. Magneto-Impedance Effect in Etched Thin Amorphous Wires. IEEE Trans Magn 1999; (35)5: 3613-15.

[9] Cobeño AF, Zhukov A, Blanco JM, Gonzalez J. Giant magnetoimpedance effect in CoMnSiS amorphous microwires $\mathrm{J}$ Magn Magn Mat 2001; (234): L359-L365.

[10] Blanco JM, Zhukov A, González J. Torsional stress impedance and magneto-impedance in $\left(\mathrm{Co}_{0.95} \mathrm{Fe}_{0.05}\right)_{72.5} \mathrm{Si}_{12.5} \mathrm{~B}_{15}$ amorphous wire with helical induced anisotropy. J Phys D Appl Phys 1999; (32)24: 3140-45.

[11] Zhukova V, Chizhik A, Zhukov A, Torcunov A, Larin V, Gonzalez J. Optimization of Giant Magnetoimpedance in Co-Rich Amorphous Microwires. IEEE Trans Magn 2002; 38(5): 3090-3092.

[12] Zhukov A, González J, Blanco JM, Vázquez M, Larin V. Microwires coated by glass: a new family of soft and hard magnetic materials. J Mat Res 2000; 15: 2107.

[13] Zhukov A. Design of the magnetic properties of Fe-rich, glasscoated microwires for technical applications. Adv Func Mat 2006; 16(5): 675-680.

[14] Hasegawa R. Non-Magnetostrictive Glassy Co-Fe-Ni-Mo-B-Si Alloys. J Appl Phys 1982; (53): 7819-7821. 
[15] Baranov SA, Larin VS, Torcunov AV, Zhukov A, Vázquez M. Nanostructured and Non-crystalline Solids, Eds. Vazquez M, Hernando A. World Scientific 1995; 567.

[16] Zhukova V, Usov NA, Zhukov A, Gonzalez J. Length effect in a Co-rich amorphous wire. Phys Rev B 2002; 65: 134407.

[17] Antonov AS, Borisov V, Borisov O, Prokoshin A, Usov N. Residual quenching stresses in glass-coated amorphous ferromagnetic microwires. J Phys D Appl Phys 2000; 33: 1161-68.
[18] Velázquez J, Vazquez M, Zhukov A. Magnetoelastic anisotropy distribution in glass-coated microwires. J Mater Res 1996; 11(10): 2499-2505.

[19] Zhukov A, Zhukova V, Blanco JM, Gonzalez J. Giant Magnetoimpedance Effect in Thin Amorphous Wires for Sensor Applications. Phys Met Metallogr 2005; (99) (Suppl): S57-S61. 